\title{
Review of the Relevance of Social Competence to Child's Development: Lessons Drawn
}

\author{
Kuranchie, Alfred, M Phil \\ Corresponding author, Catholic University College of Ghana, Sunyani, Ghana \\ Addo, Hillar, Ph D. \\ University of Professional Studies, Accra, Ghana
}

\section{Doi:10.5901/ajis.2015.v4n2p449}

\section{Abstract}

The purpose of the review was to unearth the various outcomes of being socially competent as theory and research evidence has it. Basically, major studies that examined the relevance of social competence and children's well-being were reviewed. The review has made it abundantly clear that the social and academic gains accrued from being socially competent are long lasting. Particularly, research evidence has shown that social competence provides the needed grounds for academic work to thrive hence it promotes academic excellence. Besides, socially competent children are found to be accepted in social groups and virtually do not have behaviour problems. In spite of the array of studies, which results have shown an association between social competence and academic and non-academic gains, however, the literature review suggests a need for further research concerning factors that lead to social competence or social incompetence. There is paucity of research evidence on how children acquire social competence. It, therefore, behoves educationists and researchers to expend time, energy and intellectual resources to conduct research to that effect.

Keywords: Social competence, social incompetence, social skills, academic success, social gains and child development.

\section{Purpose of the Review and Methods adopted}

Extant literature is replete with studies that have been conducted to examine the relevance of social competence on child learning outcomes. It was expedient to synthesize the scientific researches on the benefits of child social competence to inform policy decision and practice. The review specifically sought to:

i. unravel the academic and social gains of social competence; and

ii. identify the grey areas that require research attention.

The studies were obtained from both electronic and manual sources. The searches produced 35 studies conducted between 1989 and 2011, excluding those that concerned students with learning disability and behaviour problems. Google scholar was particularly helpful for locating scholarly articles written on the concept social competence. The authors have been duly acknowledged.

\section{Introduction}

The first section of the review deals with the concept of social competence. The next section sheds light on the empirically-based evidence of the benefits of social competence to people who possess it. The last section of the write-up covers conclusion and recommendations proffered to extend the discussion on the benefits of social competence.

\subsection{The Concept of Social Competence}

It is unequivocally clear that the social life of human beings demands constant interaction with people of all social standings and status. Human beings, as gregarious as we are, interact with other people on daily basis. Human survival naturally demands living in groups, where members form relationships, share their feelings, have contact and gain knowledge (Tariq \& Masood, 2011). Hence, developmental theories acknowledge the importance of social interactions in the lifetime development of humans (Knapp, 2001). The reason is that competent social behaviour is vital for normal human growth and development. The lack of competent social thinking and behaviour negates opportunities for the development and maintenance of productive social relationships (Rubin \& Rose-Krasnor, 1992). 
Social competence is an important dimension of successful adolescent growth and development. The indispensable role of social competence in human relation and interactions accounts for making it an educational objective for all students irrespective of the type of education and socio-economic background (Ten Dam \& Volman, 2007). Learners are expected to gain social competence in addition to academic knowledge they achieve when they go through formal education. Social competence is the ability to interact fruitfully with others. Researchers have focused on various definitions of social competence including social skills, acceptance by peers, skills in forming relationships, ability to solve social problems and success with social goals (Rose-Krasnor, 1997). On his part, Bierman $(2004,141)$ regards social competence as the "capacity to co-ordinate adaptive responses flexibly to various interpersonal demands and to organise social behaviour in different social contexts in a manner which is beneficial to oneself and consistent with social conventions and morals".

The concept of social competence is indexed by effectiveness and appropriateness in human interactions and relationships (Han \& Kemple, 2006). People as social beings who constantly deal with others need certain skills that would enable them achieve their ends without offending others. The skills needed for effective interpersonal functioning includes both verbal and non-verbal behaviours that are socially valued and are likely to elicit positive response from others (Osman, 2001). Possessing and utilizing both verbal and non-verbal communication skills are vital in developing and maintaining social relationships. Learners do not only have to possess good interpersonal and social skills but also utilize them efficiently. The ability to understand other people's needs and interests, acknowledge other people's strengths and weaknesses, build consensus, collaborate and co-operate with others to achieve common goals is very essential in social interactions. People who are socially competent tend to understand others' needs, show sensitivity, acknowledge and reward other people's strengths, manage conflict, collaborate and co-operate with others (Robert, 2004). In social interactions, when there is co-operation and understanding, members act and behave to the mutual benefit of all.

\subsection{Outcomes of Social Competence}

The ability to develop children's social skills has been reckoned to be an essential development task of children (Hartup, 1989, McClellan \& Katz, 1992). Social skills and competence are very essential for preparing children to mature and succeed in their adulthood roles within the family, workplace and community (Ten Dam \& Volman, 2007). In all these three settings, members interact with each other and their actions and inactions are expected to elicit positive responses. As no person lives in isolation, members of family, workplace and community depend on others and so ought to act in a socially competent manner to ensure peaceful co-existence. The benefits of being socially competent are varied and multi-faceted. Both theoretical and empirical evidence suggest that social competence yields lots of dividends to individuals who possess it.

\subsubsection{Importance of Social Competence to Academic Achievement}

Social competence is related to school readiness, which actually goes beyond fostering literacy and numeracy skills and includes developing the social-emotional skills for co-operating with others and forming and sustaining positive relationships with teachers and peers (National Council on the Developing Child, 2004). Providing children with support for school readiness is critical to their long term development (Gilliam, 2005). A longitudinal study conducted by Malecki and Elliot (2002) unearthed that social skills of $3^{\text {rd }}$ and $4^{\text {th }}$ grade students were predictive of both current and future academic performance. Suggestively, the social skills acquired at young age were related to their social skills and academic performance throughout their school years.

Wang, Haertel and Walberg (1990) examined 28 categories of variables that influence learning outcomes. It was revealed that 8 of the 11 most influential categories predicting improved academic success were related to social and emotional factors such as social interaction, relationships with peers and classroom climate. Research has also shown that children's emotional, social and behavioural adjustment is as vital to school success as cognitive and academic preparedness. It also emerged from a study that children's social and behavioural adjustment was as important as cognitive and academic preparedness (Raver \& Zigler, 1997). A research disclosed that children who had greater academic success throughout their education were socially competent when compared with their peers who did not have friends and were considered socially incompetent (Parker \& Asher, 1993).

Social relationships and social exchanges of children promote their cognitive development and social skills. Hence, school efforts of promoting students' social and emotional learning is a good approach to enhancing children's success in 
school and in life (Zins \& Elias, 2006). Children who are able to form effective and satisfying relationships with peers gain the opportunity to learn from their peers, exchange ideas and share knowledge with them, which go a long way to improve their academic fortunes. A study was also executed to ascertain the relationship between social competence and academic attainment. It emerged from the study that children who had better social skills were found to enjoy school more, get better grades and achieve more in school than children who did not possess these skills (Birch \& Ladd, 1997).

Evidence also abounds to demonstrate that successful learning requires students to interact closely with teachers and peers (Steadly, Schwartz, Levin \& Luke, 2011). Again, research evidence shows that ability to manage emotions, attention and behaviour and to form positive relationships are pre-requisites for school readiness and academic success (Blair, 2002, Denham, 2006, Payton et al, 2008). Implicitly, children who lack social competence tend to loss academically and are disadvantaged in the learning environment. Children who are challenged with paying attention, following teachers' instructions, getting on well with others and controlling negative emotions do less well in school (Ladd, Kochenderfer \& Coleman, 1997). A longitudinal survey was conducted to examine the relationship between social competence and academic competence, using structural equation model. Results supported the reciprocal model, showing that academic achievement directly influenced social competence and vice versa (Welsh, Parke, Widaman \& O'Neik, 2001). The researches have demonstrated considerable evidence supporting the notion that social competence can influence later academic competence.

Fruitful interaction requires responding to other members of the group in a co-operative manner, recognizing and accepting others' differences and compromising on decisions. Those who tend to deviate from these essential ingredients of peaceful co-existence usually experience peer rejection. A positive attitude towards the self and other people is an important aspect of social life, which makes for quality social relationship. So far, the results of the studies on the relationship between social competence and academic performance have proved positive except Galindo and Fuller (2010) study, which examined the relationship between social competence and Mathematics understanding. The findings of Galindo and Fuller (2010) study suggested no association between the two variables and the study, therefore, concluded that the competencies that Latino children bring to kindergarten and the extent to which these skills advance cognitive growth were mixed.

The results of the studies demonstrate that children's ability to manage their ability and behaviour and to make productive friendships is an essential pre-requisite for school readiness and academic achievement. Socially competent students are more academically successful, while social incompetence is a strong predictor of academic misfortune.

\subsubsection{Importance of Social Competence to Peer Acceptance}

Empirical studies have indicated that social competence also leads to social gains. There is a correlation between low social competence and behavioural problems. Research has proven that measures which have been found to increase social competence lead to reduction in behavioural problems (Wilson \& Lipsey 2007, Gundergen \& Suartdat, 2010). Pope and Ward (1995) found that children with greater social competence reported more relations with peers whereas those with lower social competence reported loneliness and social anxiety. Children who behave very well in groups and get along well with others are welcome during social activities. Socially competent children are better able to recognize emotions in facial expressions (Leppanen \& Hietanen, 2001, Wocadlo \& Rieger, 2006), which aid them to act appropriately. Children with high social competence are also more likely to have reciprocated friendship (Vaughn et al, 2000).

A study revealed that children who had at least one reciprocated friendship were rated as more socially competent by teachers, and were more liked by their peers (Linsey, 2002). It is discovered that highly developed, socially competent children have networks and are active participants within these networks (Zsolnai, 2002). This implies that children who are socially incompetent are rejected for friendship advances they make. Such people naturally would be lonely, which can affect their academic endeavour. With the collaborative learning style currently gaining currency in education settings, children need to be socially competent to enable them gain from the wisdom and knowledge of others. Children who are socially and emotionally competent also have the skills to successfully manage their emotions and behaviour, co-operate with others and form positive relationships and make responsible decisions (Collaboration for Academic, Social and Emotional Learning, 2007).

To Zins, Weissbert, Wang and Walberg (2004), individuals' social skills aid them to recognise and manage emotions, develop care and concerns for others, establish positive relationships, make responsible decisions and handle challenging situations constructively and ethically. Spence, Donovan and Brechman-Troussaint (1999) found evidence suggestive of acquisitional skills deficits. The study unveiled that socially phobic children were rated as low socially skilled 
and competent on both self and parent report. Direct behavioural observation also showed that socially incompetent children initiated social interactions less frequently, participated in fewer social interactions and were significantly less likely to produce outcomes from peers during social interactions. Also, Mostoro, Izad, Fine and Trentacosta (2002) found that social skills as a component of social competence is a good predictor of peer acceptance, especially by opposite sex peer. Children who offend others through their actions and inactions and do not communication well do not gain the acceptance of others due to the harm they may cause.

Spence (2003) contends that there is considerable evidence that social skill deficits are integral to many emotional and behavioural problems. Tariq and Masood (2011) conducted a study to investigate the relationship between social competence, parental promotion of peer relations and loneliness among adolescents. Results showed significant positive relationship between social competence and parental promotion of peer relations. However, both variables were negatively related with loneliness. Social competence has also been associated with successful school programmes, transition into school and work setting, better job opportunities and corresponding adult support and overall interactions with others (Rimm-Kaufman, Pianta \& Cox 2000). These outcomes elucidate the importance of social competence in human development and also give credence to the contribution of social competence to peer acceptance.

In addition, socially competent children have the personal knowledge and skills to engage in enjoyable interactions, activities and relationships with peers and adults (Han \& Kemple, 2006). Such individuals are able to act effectively in achieving individual and group goals. Children who are socially competent are able to decipher, which behaviour is appropriate at what time and to demonstrate it as such. Lack of social skills leads to peer rejection, isolation from peers and difficulty in making friends. Usually, children who feel lonely lack appropriate social skills or competence and the lacking affects their participation in different social activities (Adel, 2004). A study to unravel causes of loneliness among children also revealed that loneliness was associated with low social competence (Henricsson, 2006 cited in Tariq \& Massod, 2011). A study discovered an association between loneliness and interpersonal competence. Loneliness positively correlated with low levels of interpersonal competence (McGaha \& Fitzpatrick, 2005). Further, Henricsson (2006) research emphasized a relationship between loneliness and low social competence. Socially competent individuals are accepted in social groupings although Farrell's (2010) study did not find that social competence was a good predictor of peer acceptance. In the study, the participants' pro-social and anti-social behaviours were measured using sociometric and teacher rating methods. The methods of measuring the children's social competence might be inappropriate hence that results.

\subsubsection{Importance of Social Competence in Later Adult life}

It is an impregnable fact that parents and other care givers owe it a responsibility to train their children to be socially competent in their formative years to yield the expected dividends in their later years. Acquiring social skills is a major aspect of children's development (Wortham, 2002), which is needed throughout their life. Research suggests that children who do not have a basic level of social competence by age 6 may have trouble with relationships when they are adults (Ladd, 2000). It has been found that effective work performance in adults is predicted by a variety of traits such as sociability and developing social competence as a child has been highly associated with positive outcomes later on in life (Shiner, 2000).

It has been found that children who learn social and emotional skills early in life are more self-confident, trusting, empathic, intellectually inquisitive, competent in using language to communicate and capable of relating well with others (Cohen, Onunaku, Clothier \& Poppe, 2005). Respecting other people's ideas, interest and needs, recognizing and accepting other people's differences, establishing positive relationship with peers and expressing feelings appropriately are essential skills embedded in social competence. These virtues need to be promoted in all children to aid them relate very fruitfully with others at home, in school, in community and at the workplace in future.

\section{Conclusion and Suggestions for further Research}

The social interactions of individuals in academic, working and community life impose a responsibility on all those who are in-charge of child upbringing to contribute to the children's social competence building. Literature is replete with studies that have found positive and significant relationship between social competence and academic and social gains. Myriad of studies have disclosed that children who have been rated socially competent mostly by their peers and teachers have better grades and are accepted by their peers. Socially competent children are more likely to be academically successful than those who are socially incompetent, ceteris peribus. The former also are highly welcomed 
and accepted in group activities and other social groupings as they are able to assess how their actions and inactions can affect other people's feeling and hence behave appropriately than the latter. Sufficing to argue that little is known about the factors that contribute to the development of social competence than we know about the impacts of the concept on children learning outcomes. Essentially, the actual development of social competence and factors that influence it has not garnered much research attention. A pertinent question is "do children naturally develop social competence or social competence is developed with particular parenting of parents and other care givers?"

There is, therefore, the strong need for further research to investigate how to promote social competence in children. Undoubtedly, parenting strategies that contribute in building children's social competence are unknown. So, results of such studies would inform parents and significant others in the life of children to strengthen their children's capacity to manage their emotions and behaviours, and to make meaningful friendships in school to promote their school success. There is also a research need on the association between social competence and commitment, motivation and time consciousness, which are virtues of social interactions.

\section{References}

Adel, A. M. E. (2004). Effects of interaction between parental treatment styles and peer relations in classroom on the feeling of Ioneliness. Doctoral Dissertation, Tubuigen University.

Blair, C. (2002). School readiness: Integrating cognitive and emotion in a neurobiological conceptualization of children's functioning at school entry. American Psychologist, 57, 111-117

Cohen, J., Onunaku, N., Clothier, S. and Poppa, J. (2005). Helping your children succeed: Strategies to promote early childhood social and emotional development. Washington, DC: National Conference of State Legislatures.

Collaboration for academic, social and emotional learning (2007). Background on social and emotional learning. Chicago: University of Chicago Press.

Denham, S. A. (2006). Social-emotional competence as support for school readiness: What is it and how do we assess it? Child Study Journal, 24(1), 1-21.

Farrell, A. M. (2010). Social competence and its relationship to peer preference in pre-schoolers. A Master's Thesis. Brandeis University.

Galindo, G. and Fuller, B. (2010). The social competence of Latino Kindergarten growth in Mathematics understanding. Development Psychology, 46(3), 579-592.

Gilliam, W. (2005). Pre-kindergarteners left behind: Expulsion rates in state pre-kindergarten systems. New Haven, CT: University Child Study Center.

Han, H. J. and Kemple, K. M. (2006). Components of social competence and strategies of support: Considering what to teach and how. Early Childhood Education Journal, 34(3), 241-246.

Hartup, W. W. (1989). Social relationships and their developmental significance. American Psychologist, 120-126

Knapp, K. (2001). Social competence of children: Definitions and assessment.

Ladd, G. W., Kochenderfer, B. J. and Coleman, C. (1997). Classroom peer acceptance, friendship and vitimisation: Distinct relational systems that contribute uniquely to children's school adjustment. Child Development, 68, 1181-1197.

Lapanen, J. M. and Hietman, J. K. (2001). Emotional recognition and social adjustment in school-aged girls and boys. Scandinavian Journal of Psychology. 42(5), 429-435.

Linsey, E. W. (2002). Pre-school children friendships and peer acceptance: Links to social competence. Child Study Journal, 32(3), 145156.

Malecki, C. K. and Elliot, S. N. (2002). Children's social behaviour as predictors of academic achievement: A longitudinal analysis. School Psychology quarterly, 17, 1-23.

McClelland, D. E. and Katz, L. C. (1993). Young children's social development: A checklist. Urbana, IL: Clearinghouse on Elementary and Early Childhood Education.

National Council on Developing Child (2004). Young develop in an environment of relationship. Working Paper № 1.

Osman, B. (2001). Nurturing social capital in a child with learning disabilities. Disabilities, 4(2), 56-67.

Parker, J. G. and Asher, S. R. (1993). Friendship and friendship quality in middle childhood: Links with peer group acceptance and feeling of loneliness and social dissatisfaction. Development Psychology, 29(4), 611-621.

Payton, J., Weissberg, R., Durlock, J., Dymniki, A., Taylor, R., Schellinger, K., and Pachen, M. (2011). The positive impact of social and emotional learning for kindergarten to eight grade students: Findings from three scientific studies. Chicago, IL: CASEL

Pope, A. and Ward, J. (1995). Factors associated with peer social competence in children with anomalies. Journal of Pediatrics Psychology, 22(4), 455-469.

Raver, C. C. and Zigler, E. F. (1997). Social competence: An untapped dimension in evaluating Head Start success. Early Childhood Research Quarterly, 12, 363-385.

Rimm-Kaufman, S. E., Pianta, R. C. and Cox, M. J. (2000). Teachers' judgments of problem in the transition to kindergarten. Early Childhood Research Quarterly, 15, 147-166.

Robert, E. (2004). Emotional competence framework. Journal of Counseling and Development, 231-239.

Rose-Krasnor, L (1997). The nature of social competence: A theoretical review. Social Development, 6(1), 111-135. 
Rubin, K. H. and Rose-Krasnor, L. (1992). Interpersonal problem solving and social competence in children. In V. B. Hasselt and M. Hersen (eds.). Handbook of social development: A lifespan perspective. New York: Plenum.

Spencer, S. H., Donovan, C. and Brechman-Troussaint, M. (1999). Social skills, social outcomes and cognitive features of childhood phobia. Abnormal Psychology, 108, 211-221.

Shiner, R. (2000). Linking childhood personality adaptation: Evidence from continuing and changes across time into later adolescence. Journal of Personality and Social Psychology, 78(2), 310-325.

Tariq, T. and Masood, S. (2011). Social capital, parental promotion of peer relations and loneliness among adolescents. Pakistan Journal of psychological Research, 26(2), 217-232.

Ten Dam, G. K. and Volman, M. (2007). Educating for adulthood or for citizenship: Social competence as an educational goal. European Journal of Education. 42(2), 281-298.

Vaughen, S., Hogan, A., Kouzekanani, K. and Shapiro, S. (1990). Peer acceptance, self-perception and social skills of learning disabled students prior to identification. Journal of Educational Psychology, 82, 101-106.

Wang, M., Heartel, G. and Walberg, H. (1990). What influences learning?: A content analysis of review literature. Journal of Educational Research, 84(1), 30-34.

Welsh, M. Parke, R. D., Widaman, K and O'Neil, L. (2001). Linkages between children's social and academic competence: A longitudinal analysis. Journal of School Psychology, 38(6), 463-481.

Wocadlo, C. and Rieger, I. (2006). Social skills and non-verbal decoding of emotions in very preterm children at early school age. European Journal of Development Psychology, 3(1), 48-70.

Zins, J. and Elais, M. (2006). Social and emotional learning: Promoting the development of all pupils. Journal of Educational and Psychological Consultation, 17(2\&3), 233-250.

Zsolnai, A. (2002). Relationship between children's social competence, learning motivation and school achievement. Educational Psychology, 22(3), 317-329. 